\title{
LA ACCIÓN DE INAPLICABILIDAD DE PRECEPTOS LEGALES
}

\author{
LAUTARo Ríos Álvarez ${ }^{*}$
}

RESUMEN: En el presente trabajo se bace un breve repaso bistórico del control de constitucionalidad de la ley, particularmente centra su análisis en la acción de inaplicabilidad de preceptos legales. El estudio parte con la situación de la Carta de 1833, para luego centrarse en el recurso de inaplicabilidad de la Constitución de 1925, culminando con el actual campo atributivo del Tribunal Constitucional, después de la reforma de 2005, que le permite conocer exclusivamente de la acción de inaplicabilidad.

Palabras Clave: Acción de inaplicabilidad - Control de constitucionalidad de la ley - Tribunal Constitucional.

\section{ACTION OF INAPPLICABILITY OF LEGAL PRECEPTS}

ABSTRACT: This article makes a brief bistorical review of the constitutionality control of the law, particularly focusing its analysis in the action of inapplicability of legal precepts. The study begins with the situation of the Constitution of 1833. It then focuses in the action of inapplicability of the Constitution of 1925, finishing with the current field of attributions of the Constitutional Court, after the reform of 2005, permitting it to know of the action of inapplicability exclusively.

KEY WORDS: Action of Inapplicability - Constitutionality control of the law - Constitutional Court.

SUMARIO: 1. Noción bistórica y solución jurídica bajo la C.P.R. de 1833. 2. El recurso de inaplicabilidad y la inaplicabilidad de oficio en la C.P.R de 1925. 3. Naturaleza de la acción de inaplicabilidad y sus diferencias con la acción de inconstitucionalidad. 4. Tesis jurisprudencial de la Excma. Corte Suprema sobre la procedencia de la inaplicabilidad. 5. La Reforma Cons-

Abogado. Doctor en Detecho por la Universidad Complutense de Madrid (España). Profesor de Derecho Constitucional, Universidad de Valparaíso. Correo electrónico: estudiorios@entelchile.net

Fecha de recepción: 30 de octubre de 2007

Fecha de aprobación: 30 de noviembre de 2007. 
titucional de la Ley $N^{o} 20.050$ de 2005. 6. Improcedencia de la acción de inaplicabilidad de los Tratados. 7.- Tramitación del requerimiento. 8.- Efectos de las sentencias de inaplicabilidad.

\section{NOCIÓN HISTÓRICA Y SOLUCión JURÍDICA BAJO LA C.P.R. DE 1833}

Comúnmente se cree que, bajo la vigencia de la Carta de 1833, las autoridades de nuestro país no se interesaron en el tema del control de la constitucionalidad de la ley, bajo el supuesto de que esta preocupación incumbía a los órganos colegisladores y, en especial, al Presidente de la República quien debía "concurrir a la formación de las leyes con arreglo a la Constitución; sancionarlas y promulgarlas" (Art. $73 \mathrm{~N}^{\mathrm{o}} 1$ ).

1.1. A raíz de una consulta del Intendente de Concepción, la Corte Suprema emitió un dictamen a petición del Gobierno, el 17 de junio de 1848, que en lo pertinente, decía:

“... el Tribunal observatá que ninguna magistratura goza de la prerrogativa de declarar la inconstitucionalidad de las leyes promulgadas después del Código fundamental y de quitarles por este medio sus efectos y su fuerza obligatoria. Ese poder, que por su naturaleza sería superior al del legislador mismo, puesto que alcanzaría a anular sus resoluciones, no existe en magistratura alguna, según nuestro sistema constitucional. El juicio supremo del legislador, de que la ley que dicta no es opuesta a la Constitución, disipa toda duda en el particular y no permite retardos o demoras en el cumplimiento de sus disposiciones"

1.2. No obstante lo anterior, la misma Corte Suprema, en Circular dirigida a las Cortes de Apelaciones del país el 2 de enero de 1867, las instruía así:

"Las autoridades encargadas de aplicar las leyes a un caso determinado, deben no obstante, dar preferencia en el asunto especial en que se ocupan, a la Constitución si estuviera en clara y abierta pugna con ellas, de la misma manera que a estas autoridades compete, no siendo claro su sentido, penetrar su verdadero espíritu, fijar la legítima inteligencia, esto es, interpretarlas para los efectos del juicio especial que van a pronunciar"2.

Sería ilustrativo averiguar si los jueces -incluida la Corte Supremahicieron uso de tan interesantes instrucciones.

ROLDÁN, A. (1914) Elementos de Derecho Constitucional de Chile. Santiago, p. 518. También HuneEus, J. (1891) La Constitución ante el Congreso. Tomo II. Santiago: Imp. Cervantes, p. 239.

2 SIlva BASCUÑÁN, M. La Constitución ante los Tribunales. Citado por Silva BASCUÑ ÁN, A. (1963) Tratado de Derecho Constitucional. T. III. Santiago: Editorial Jurídica de Chile, p. 432. 
1.3. El más notable comentarista de la Carta de 1833, don Jotge Huneeus, después de transcribir el dictamen citado en 3.1., señala que esa misma fue la opinión del Ejecutivo en la nota enviada a la Corte Suprema, el 28 de agosto de 1876, respondiendo a observaciones de esta sobre la inconstitucionalidad de una delegación de facultades del Congreso en el Presidente. La respuesta decía así:

“¿Dirá ahora V.E. que esa delegación fue inconstitucional? Pero, si lo dice, ¿contra quién podría dirigir ese cargo? ¿Será contra el Congreso, por haber violado la Carta Fundamental, al otorgar aquella autorización? El Tribunal verá si semejante facultad entra en el círculo de sus atribuciones, que, por lo que hace al Presidente de la República y al Consejo de Estado, están muy tranquilos con el cumplimiento del mandato del Congreso, en uso de la autorización que él les confirió".

Y más adelante, la nota añadía:

"La única misión de V.E., conforme exactamente con la de los demás Tribunales, está reducida á la recta aplicación de las Leyes á los casos particulares que ocurren en las causas sometidas á sus fallos, sin que sea lícito evadir su cumplimiento, ya porque sean justas ó injustas, ya por ser conformes ó contrarias á la Constitución".

Esta opinión, por lo demás, era plenamente compartida por don Jorge Huneeus, y así lo hace constar en su comentario, reforzándolo con la cita del art. $4^{\circ}$ de la Ley de 1875 , sobre Organización y Atribuciones de los Tribunales, que prohibía al Poder Judicial "mezclarse en las atribuciones de otros poderes públicos"3.

1.4. En resumen $-y$ con la prevención del instructivo de la Corte Suprema recordado en 1.2.- no conocemos ninguna decisión judicial librada bajo la vigencia de la Carta de 1833 que inaplicara una ley contraria a la Constitución, pese a que varias disposiciones de esta habrían podido dar pie para actuar en ese sentido ${ }^{4}$.

\section{EL RECURSO DE INAPLICABILIDAD Y LA INAPLICABILIDAD DE OFICIO EN LA C.P.R. DE 1925}

El control de constitucionalidad de la ley no es más que una garantía instrumental del principio de supremacía de la Constitución.

Este principio comporta situar a la Constitución como la primera y la fuente matriz de todas las normas, "lex superior-como dice García de 
Enterría- aquella que sienta los valores supremos de un ordenamiento y que desde esa supremacía es capaz de exigir cuentas, de erigirse en el parámetro de validez de todas las demás normas jurídicas del sistema"5.

Los juristas norteamericanos fueron coherentes al establecer el mecanismo de la judicial review como sistema de control judicial de la constitucionalidad de la ley.

Reclamaron para todo el Poder Judicial -y no solo para su cúpula- la incumbencia y el deber de "manifestar en qué consiste la ley" y de interpretar los preceptos que deben aplicar. Señalaron que, en caso de contradicción entre la ley y la Constitución, "el tribunal debe determinar cuál de estos ordenamientos en pugna debe normar el caso". Y -a continuación- asentaron, con la fuerza debida, que "Lo anterior radica en la esencia misma del ejercicio de la justicia". Para concluir que "si entonces los tribunales se basan en la Constitución y esta es superior a cualquiera disposición ordinaria de la legislatura, la Constitución, y no ese decreto (esa ley) común, debe regir el caso al cual ambas se aplican" (Fallo Marbury vs. Madison de 1803).

Los constituyentes de 1925 se llenaron la cabeza de fantasmas que les impidieron ver con claridad que o se establecía un sistema de control difuso, como el norteamericano, o no existiría en Chile un control eficiente de la constitucionalidad de la ley, como fue el lamentable resultado.

En los debates de la Subcomisión encargada de su estudio, don Luis Barros Borgoño expresó “... la conveniencia que habría en establecer en la nueva Constitución algún poder o autoridad que determine si las leyes que en lo sucesivo se dicten, van o no contra los principios constitucionales. Tal poder o autoridad es en los Estados Unidos de América, la Corte Suprema. Entre nosotros podría serlo también nuestra Corte Suprema, o una Corte Especial".

El Presidente, don Arturo Alessandri, advirtió que “... en el proyecto de reforma que él ha elaborado, se contempla una disposición de esta naturaleza en el título relativo a la Administración de Justicia".

Entonces don Romualdo Silva observó que "convendría agregar que el tribunal conociera también de las reclamaciones que se hicieran contra disposiciones legales contrarias a la Constitución..." A lo que el Presidente Alessandri replicó que en ello "habría un grave peligro, porque se constituiría el Tribunal en Poder Legislativo..."6.

En la sesión del 8-VI-25 el St. Alessandri propuso introducir la siguiente disposición: "La Corte Suprema velará especialmente por el respeto de esta Constitución y en el caso especial en que conozca, podrá declarar sin efecto cualquier precepto legal contrario a ella".

\footnotetext{
5 GARCÍA DE ENTERRÍA, E. (1984) La Constitución como norma y el Tribunal Constitucional. Madrid: Civitas.

6 "Actas Oficiales", ses. $\mathrm{N}^{\circ} 7$ de 12-V-1925, p. 81.
} 
El Sr. Vicuña hizo indicación de que esta facultad de la Corte pudiera ejercerse no solo en casos particulares "sino también en general". Entonces el Presidente Alessandri insistió en que, con esa fórmula se daría a la Corte más poder que al propio Presidente y al Congreso, arguyendo que siendo así que "como existe la tendencia humana a acentuar las propias facultades, dicho tribunal enmendaría a menudo la obra legislativa, declarando sin fuerza, por inconstitucionales, las leyes que se dictasen, es decir, asumiendo en el hecho todo el poder, cuando su papel debe ser pasivo y no activo" 7 .

No obstante, para ser justos, debe recordarse que en la Sesión N $^{\circ} 28$ el Sr. Alessandri expresó que, "después de haber meditado mucho sobre esta materia", proponía la siguiente fórmula: "Los Tribunales de Justicia, en los negocios de que conozcan con arreglo a la ley, aplicarán preferentemente los preceptos de esta Constitución cuando entre ellos y las leyes hubiere oposición". Era una disposición digna de Perogrullo; pero, en fin, algo decía a quienes aplican los principios -aun los más elementalessolo cuando los ven puestos por escrito.

Sin embargo, ni siquiera esta inocua proposición logró ahuyentar a los fantasmas.

Don Eliodoro Yáñez alegó que esa prerrogativa correspondía solo a la Corte Suprema ya que, de no ser así, podría producirse "una grave perturbación en la administración de justicia". No explicó por qué ni a qué clase de perturbación se refería. Verdad es que, tampoco, nadie se lo preguntó.

El Sr. Vicuña Fuentes, por su parte, sin acordarse de que estaban delibetando sobre la primacía de la Constitución, hizo presente "que solo toca al legislador explicar o interpretar la ley de un modo generalmente obligatorio"...8.

En definitiva se encargó a don José Maza la redacción de este artículo que fue aprobado finalmente con el siguiente texto:

"Art. 86. La Corte Suprema tiene la superintendencia directiva, correccional y económica de todos los Tribunales de la Nación, con arreglo a la ley que determine su organización y atribuciones.

"La Corte Suprema, en los casos particulares de que conozca o le fueren sometidos en recurso interpuesto en juicio que se siguiere ante otro Tribunal, podrá declarar inaplicable, para ese caso, cualquier precepto legal contrario a la Constitución. Este recurso podrá deducirse en cualquier estado del juicio, sin que se suspenda su tramitación.

\footnotetext{
7 "Actas", ses. No 19, 8-VI-25, p. 254.

8 "Actas." ses. N 28 de 9-VII-25, p. 366.
} 
"Conocerá, además, en las contiendas de competencia que se susciten entre las autoridades políticas o administrativas y los Tribunales de Justicia que no correspondan al Senado"?.

La reducida envergadura de la que quedó dotado el recurso de inaplicabilidad fue el fruto de una conjunción de temores paralizantes más que de un espíritu resuelto a proteger vigorosamente la supremacía de la Constitución.

Esas alas endebles, que no servían para volar muy lejos, fueron recortadas aun más por la propia Corte Suprema y por el legislador. En efecto, como lo recordara el presidente de dicha Corte, Sr. Eyzaguirre, en la elaboración de la Carta del $80^{10}$, del texto transcrito se desprende en forma inequívoca que cualquiera de sus Salas podía conocer del recurso, puesto que este era procedente "en los casos particulares de que conozca (la Corte Suprema)" o en los recursos interpuestos en juicio; de todos los cuales dicha Corte conoce en Sala. No obstante lo cual el Auto Acordado del Tribunal Supremo de 22-III-1932, dispuso su conocimiento por el Tribunal Pleno. Y otro tanto hizo después el legislador al aprobar el texto del art. $96 \mathrm{~N}^{\circ} 1$ del Código Orgánico de Tribunales.

Numerosos estudios procesales, de derecho sustantivo y estadísticos han demostrado que se trataba de un recurso poco eficaz, fuera del alcance del común de la gente, lento y paralizante.

\section{NATURALEZA DE LA ACCIÓN DE INAPLICABILIDAD Y SUS DIFE- RENCIAS CON LA ACCIÓN DE INCONSTITUCIONALIDAD}

3.1. Atendida su naturaleza particular, la inaplicabilidad cumple la función de impedir que la parte que la invoca en el caso concreto del que conoce un tribunal, se vea afectada por un precepto legal cuya aplicación a ese caso particular resulte evidentemente contraria a la Constitución y, especialmente, a los fines perseguidos por esta. De allí que en este instituto procesal -además del juez y de las partes- comparecen tres elementos de cotejo necesarios para su decisión, a saber: la norma constitucional, el precepto legal cuya inaplicación se solicita y -lo más específicamente

9 Sobre la historia de este recurso puede verse: RAVEAU, R. (1939) Tratado Elemental de Derecho Constitucional Chileno y Comparado. Santiago: Editorial Nascimento, pp. 379-392; Estevez GazMuRI, C. (1949) Elementos de Derecbo Constitucional Chileno. Santiago: Editorial Jurídica de Chile, pp. 340-347; SILVA BASCUÑ́N (1963). T. III, Pp. 432-445; ANDRADE GEYWITZ, C. (1963) Elementos de Derecho Constitucional Cbileno. Santiago: Editorial Jurídica de Chile, pp. 597-602.

10 Don José María Eyzaguirre Echeverría, Presidente de la C. Suprema y de la Subcomisión de Organización y Atribuciones del Poder Judicial, en la Ses. del 19-X-1976 de Ia Comisión de Estudio de la Nueva Constitución -en lo sucesivo, "C.E.N.C."- Actas Oficiales, Ses. No 251, p. 146. 
decisivo- el examen particular acerca de si, en ese caso, la aplicación del precepto cuestionado pudiera generar efectos opuestos a la finalidad implícita de aquella.

Esta tesis ha sido expresamente acogida por el Excmo. Tribunal Constitucional en la Sentencia de Inaplicabilidad de fecha 9-XI-2006, recaída en el Rol $N^{0} 529$, en cuyo Considerando decimoquinto la reproduce textualmente.

Por su misma particularidad, es propio de la naturaleza de la inaplicabilidad, que su fallo estimatorio tenga efectos jurídicos inter partes, es decir, restringidos al caso examinado y resuelto y a quienes fueron partes en él, siguiendo la regla de toda sentencia judicial ${ }^{11}$.

3.2. La inaplicabilidad de una ley puede afectar a cualquiera persona que sea parte en el caso sub-lite; de allí que esté legitimada para impetrarla quienquiera se encuentre en tales circunstancias en una causa en actual tramitación.

La inconstitucionalidad de una ley, en cambio, afecta a la coherencia del orden jurídico y a la nación entera que se rige por su Ley Fundamental. De allí que la legitimación activa para plantear la respectiva cuestión esté limitada a ciertos órganos que representan ese interés - generalmente los órganos legislativos o una proporción de sus miembros- otros órganos específicamente individualizados o un número considerable de ciudadanos ${ }^{12}$.

3.3. El procedimiento de la inaplicabilidad exige siempre el examen del caso particular -sin intervenir en los hechos y probanzas que son materia reservada a los jueces del fondo-y de la manera en que la aplicación a ese caso de la norma legal cuestionada, puede vulnerar la Constitución. De allí que, en la tramitación de este asunto, pueda pedirse y decretarse la suspensión del procedimiento de la causa en que incide mientras pende el pronunciamiento acerca de la inaplicabilidad y tenerse a la vista los antecedentes del caso.

El procedimiento de la inconstitucionalidad es más simple y más directo porque su objeto es un análisis teórico acerca de la compatibilidad o incompatibilidad de dos normas generales y abstractas, sin incidencia en ningún caso concreto.

3.4. Por todas estas diferencias puede advertirse que hay preceptos legales que pueden estar en perfecta consonancia con la Carta Fundamental y, no obstante ello, ser inaplicables a un caso particular, precisamente

\footnotetext{
11 Ver el art. $3^{\circ}$ inciso $2^{\circ}$ del Código Civil.

12 En la Constitución peruana ese número es de 5.000. En la de Ecuador es de 1.000 ciudadanos.
} 
porque en la particularidad de ese caso, la aplicación de la norma legal objetada contraría los efectos previstos por la norma constitucional.

En la génesis de la Carta del 80, el entonces Presidente de la Corte Suprema y Presidente de la Subcomisión sobre el Poder Judicial, don José María Eyzaguirre Echeverría, a propósito de una disposición del Proyecto -que prescribía que "Después de tres fallos, en un mismo sentido, acogiendo el recurso, la inaplicabilidad producirá efectos generales"- hizo una referencia ejemplar a esta materia. Dijo lo siguiente:

"En la práctica, se ha visto que a veces la Corte Suprema falla un mismo punto de inaplicabilidad diez, veinte o treinta veces. El tribunal y la Subcomisión, entonces, creen que hacerlo pronunciarse reiteradamente sobre la misma cuestión conduce a que las partes incurran en un gasto inútil y en pérdida de tiempo. Así ha ocurrido, por ejemplo, con un artículo de la Ordenanza General de Construcciones. Los presentes, quienes son todos abogados, sabrán que había un artículo que (en caso de expropiación) disponía el pago del avalúo fiscal o de un tanto por ciento más del avalúo y que la Corte Suprema declaró inconstitucional en virtud del antiguo texto del $\mathrm{N}^{\circ} 10$ del artículo 10 (de la Constitución de 1925). Después también hubo varios casos como, por ejemplo, el de la pequeña propiedad trabajada por su dueño o el de la casa habitada por su propietario, en los que han debido pronunciarse unas quince o veinte sentencias en cada caso, por lo menos, declarando la Corte Suprema la inaplicabilidad de una ley que contraviene los preceptos constitucionales"13.

En la cita precedente, se dan dos ejemplos que pertenecen, el primero, al ámbito de la inconstitucionalidad, toda vez que la norma de la Ordenanza citada era opuesta a la Carta Fundamental in abstracto, bastando el simple cotejo de la norma constitucional con la legal para advertir su carácter contrario a la Constitución en términos generales. En cambio, el segundo ejemplo se refiere a la inaplicabilidad propiamente tal; puesto que las leyes expropiatorias que ordenaban el pago de la indemnización a plazo estaban perfectamente acordes con la Constitución vigente, cuyo artículo $10 \mathrm{~N}^{\circ} 10$, en lo pertinente, establecía que “El expropiado tendrá siempre derecho a indemnización cuyo monto y condiciones de pago se determinarán equitativamente, etc." y agregaba más adelante: "La ley determinará las normas para fijar la indemnización, el tribunal que conozca de las reclamaciones sobre su monto, (...) la forma de extinguir esta obligación, etc." De tal modo que una ley expropiatoria con pago a plazo estaba en concordancia con la Constitución. Sin embargo, no ocurría lo mismo en el caso particular de que el bien expropiado fuese una "pequeña propiedad rústica trabajada por su dueño" o "la vivienda habitada por su propieta- 
rio", quienes "no podrán ser expropiados sin previo pago de la indemnización". Estas garantías, establecidas en la misma disposición constitucional, exigían la prueba del hecho en que se fundaba la facultad de exigir el pago previo de la indemnización; pero, una vez probado, requerían la declaración de inconstitucionalidad de la ley expropiatoria para ese caso particular.

Es, entonces, perfectamente razonable que dicha declaración tenga efecto inter partes en el caso en que se pronuncia, quedando vigente el precepto legal por no ser, en su generalidad, opuesto a la Constitución.

3.5. Por otra parte, quien fue un destacado miembro de la Comisión de Estudio de la Nueva Constitución y el más autorizado y prolífico comentarista de ella, el profesor Alejandro Silva Bascuñán, en su segundo "Tratado de Derecho Constitucional", refiriéndose al recurso de inaplicabilidad, aborda el tema de la manera siguiente:

"No hay duda, por cierto, desde luego, de que un elemento esencial de la decisión habrá de incidir en el enfrentamiento del contenido dispositivo sustancial de la norma legal con el de los preceptos pertinentes de la Carta.

"La complejidad nace, entre tanto, en la determinación de si basta o no ese punto de vista.

"En nuestra opinión, el aspecto que acabamos de puntualizar no precisa de modo completo el criterio que debe guiar a la Corte en el uso de la facultad, por cuanto la sustancia de la atribución no se reduce a lo puramente abstracto, sino que ha de ser proyectada al caso. En otras palabras, partiendo de una precisión sólida del contenido sustantivo de lo prescrito en la Constitución, la Corte debe avanzar y, con tal base, analizar luego si la conformidad o disconformidad del precepto legal con la Carta - deducida tan solo de una simple confrontación teórica de ambas normativas- permanece al proyectarla en la situación específica en análisis".

"¿En qué se afirma nuestro parecer de que la tarea de la Corte, cuando se trata del art. 80 , no es simplemente debatir y definir una conclusión abstracta?

"Proviene de la constatación de que, por seria y profunda que sea la gestación de un precepto legal, por firme y sólida que haya sido la reflexión de los órganos colegisladores, en cuyo análisis hayan procurado ponerse en el caso de todas las situaciones previsibles, la vastedad, densidad y variedad del ordenamiento jurídico, la complejidad de la conducta humana y la infinidad de las distintas expresiones de la actividad y propósitos de los integrantes de la sociedad política, hacen que, en el hecho, sea absolutamente imposible o casi imposible, para quienes redactan la ley, imaginar y tener en cuenta todas las proyecciones que pudieran derivarse del texto legal y abarcar y comprender consecuentemente en su 
dispositivo todos los casos particulares en los cuales el precepto vaya a hacerse efectivo.

"Es por eso que, llevado lo abstracto de la norma a lo concreto de su aplicación, ella puede ser constitucional o inconstitucional según las características de los problemas específicos que se presenten".

Añade más adelante:

"Desconocer la densidad del problema jurídico y calificar la atribución de la Corte como de naturaleza estrictamente doctrinaria, de simple parangón entre la sustancia del precepto legal y la de la norma constitucional, es no percibir la diversidad de tarea del legislador y la del juez.

"Expresión de la realidad de que el problema que analizamos presenta los rasgos definitorios que venimos sosteniendo, lo pone de manifiesto constantemente el Tribunal Constitucional, cuando, por ejemplo, al examinar determinado proyecto de ley -precisamente en razón de que su deber no se limita a plantear y pronunciarse sobre cuestiones puramente doctrinarias sino representarse, hasta donde esté a su alcance, las características y modalidades concretas de los casos específicos que podrán surgir al aplicarse los preceptos de la ley en gestación--, acompaña también su pronunciamiento con entendidos, supuestos o reservas para advertir que en tales o cuales hipótesis o eventualidades el precepto será o no será constitucional"14.

En otro trabajo anterior, el profesor Silva Bascuñán había expresado: “...si la índole de la misión confiada a la Corte Suprema es análoga a la del Tribunal Constitucional en el resguardo de la supremacía constitucional frente a la actuación del legislador, el sentido y alcance de la tarea de uno y otro órgano revisten caracteres diferentes...

"El Tribunal Constitucional, en efecto, al comparar la sustancia preceptiva de una ley con la de la Carta, debe efectuar una tarea de tipo puramente abstracto, general y predeterminado, puesto que, siendo de diferente jerarquía el precepto legal y el constitucional, participan del rasgo común de ser reglas llamadas a regir en todas las situaciones particulares, concretas, específicas comprendidas en sus respectivos términos.

"Mientras tanto, la Corte Suprema, en el ejercicio de su facultad de declarar la inaplicabilidad, no puede limitarse a una apreciación basada solo en comparar el contenido dispositivo de las normas pertinentes de la Carta con el de los preceptos legales vinculados al caso.

"Se impone, como requisito ineludible para pronunciar la declaración por la Corte Suprema, que esta considere la situación de hecho en relación a la cual está analizando la posibilidad de ejercer su atribución".

Y, más adelante, concluía: "Será, pues, en la doble premisa de la realidad fáctica y de estar esta enmarcada en el precepto legal, que el

14 SILVA BASCUÑÁN, A. (2002) Tratado de Derecbo Constitucional. T. VIII. Santiago: Editorial Jurídica de Chile, pp. 194-199. 
Tribunal Supremo habrá de adentrarse a dilucidar acerca de si la aplicación de la ley al caso en examen representa una pugna con la superior normativa contenida en la Constitución"15.

\section{Tesis jurisprudencial de la Excma. Corte Suprema sobre LA PROCEDENCIA DE LA INAPLICABILIDAD}

En abierta discrepancia con las razones expuestas precedentemente y que comparto, la Excma. Corte Suprema desarrolló una doctrina reductiva que permitía la procedencia del recurso solo cuando el recurrente lograba demostrar que la norma legal impugnada era, "per se", incompatible con la Constitución, sin que fuera relevante examinar la aplicación de aquella al caso sub lite.

Esta doctrina, expresada en numerosos fallos, se desarrollaba así:

" ${ }^{\circ}$ Que, del tenor literal de la norma transcrita (art. 80 de la Constitución) resulta que la declaración de inaplicabilidad procede cuando el precepto a que ella se refiere es 'contrario a la Constitución'. Ello quiere decir que la norma cuya inaplicabilidad se pretende, sea declarada para el caso particular, considerada en abstracto, pugna con las disposiciones de superior jerarquía contenida en la Carta Fundamental; en otras palabras, significa que el mandato, prohibición o permiso contenido en la norma cuestionada, contrasta en general con aquellos que se consagran en la Constitución, de manera que el precepto constitucional resulta incompatible con la norma impugnada 'en sî', y no solo con la forma específica en que esta última pretende aplicarse en el caso concreto de que se trata.

" $3{ }^{\circ}$ Que, como puede deducirse de lo relacionado en la parte expositiva de esta sentencia, este no es el caso en el asunto sub lite. En efecto, el recurrente no pretende sostener que el artículo $5^{\circ}$ de la ley 18.377 sea de suyo contrario a la Carta Fundamental; afirma, más bien, que al intentar aplicárselo a él, en su situación específica, se produciría un resultado contrario al art. 19 N 24 de la Constitución Política de la República. Pero, obviamente, una consecuencia inconstitucional es la que casi siempre se sigue cada vez que se yerra en la aplicación concreta de una cierta disposición, lo cual no implica, en modo alguno, que esta última sea en sí inconstitucional" 16 .

15 SIrV̌a BASCuñán, A. (1988) "Efectos de la resolución de Constitucionalidad". Revista Chilena de Derecho, Vol. 15, Nos. 2-3.

16 Fallo de inaplicabilidad "Fuenzalida Navarrete, Gastón", de fecha 28-VIII-1998. Gaceta Jurídica, $\mathrm{N}^{\circ} 218$, agosto/98, p. 83. Ver también en Revista de Derecbo y Jurisprudencia, t. 94, 2.5, p. 77; inaplicabilidad en "Ríos Arias"; en el mismo tomo "Sociedad Agrícola Covadonga" 2.5 p. 83; en el tomo 93, 2.5, p. 157, "Banco Osorno"; tomo 92, 2.5 p. 83, "Compañía Minera Tamaya", todos rechazados o declarados inadmisibles. 
Esta doctrina no solo confunde los presupuestos y fines del recurso de inaplicabilidad -que es de su competencia exclusiva- con los de la acción de inconstitucionalidad, que es de naturaleza distinta y persigue otra finalidad. La gravedad de esta doctrina consiste en coartar el conocimiento del recurso de inaplicabilidad en situaciones en que sería perfectamente procedente, imponiéndole al recurrente la carga jurídica de evidenciar la contradicción in abstracto de la norma impugnada con la Constitución, la que no es propia del recurso y que no le corresponde asumir ni demostrar; prescindiendo -en cambio- de lo esencial que es, precisamente, la particularidad del caso en que la inaplicabilidad se suscita y el examen de cómo en ese caso, y no en términos generales y abstractos, el espíritu, la finalidad o los efectos previstos en la norma Constitucional pueden resultar vulnerados.

Es cierto que un recurso de inaplicabilidad puede abordar un problema de inconstitucionalidad general del precepto legal cuestionado. Es verdad que, en ese evento, la sentencia estimatoria del recurso, debido a su efecto inter partes, deja subsistente la ley inconstitucional y genera una situación de desigualdad entre el favorecido con la sentencia y quienes no fueron parte en el litigio respectivo.

Pero para subsanar un mal no puede incurrirse en una confusión entre dos instituciones distintas, al extremo de identificarlas, generando un remedio que puede resultar peor que la enfermedad. Lo correcto, en esta circunstancia, es instaurar directamente la acción de inconstitucionalidad.

\section{LA Reforma Constitucional de la LeY $\mathrm{N}^{\circ} 20.050$ De 2005}

La Ley $\mathrm{N}^{\circ} 20.050$ introdujo una transformación substancial en la acción de inaplicabilidad.

Examinaremos el traslado de la radicación de su competencia desde la Corte Suprema al Tribunal Constitucional (en adelante también T.C.); veremos a continuación la esclarecedora redacción del art. $93 \mathrm{~N}^{\circ} 6$; y analizaremos la interesante innovación que significa la titularidad actual de la acción de inaplicabilidad, sin descuidar el trámite previo de admisibilidad, cuando procede.

\subsection{Traslación de la competencia para conocer de la inaplicabilidad de la ley}

No solo existen estudios empíricos acerca de la ineficacia que acompañó la vigencia del recurso de inaplicabilidad bajo su sometimiento a la jurisdicción de la E. Corte Suprema sino que también parece evidente que la inserción del T.C. en el ordenamiento orgánico chileno debió reunir, bajo la competencia de este, el control de constitucionalidad de 
la ley en todas sus formas y fases; esto es, tanto el control abstracto como el concreto de constitucionalidad y tanto el de carácter preventivo como el de efecto correctivo de este importante instrumento de defensa de la supremacía de la Constitución.

La mantención de la acción en estudio bajo la órbita de competencia de la Corte Suprema, después de la instauración del T.C., produjo una dualidad de judicaturas supremas, a cargo de asuntos de naturaleza similar, que no solo transgredía el principio de unidad de jurisdicción sino que arrastraba la perniciosa consecuencia de duplicidad de criterios interpretativos en una misma materia.

Ha sido, pues, un avance significativo ${ }^{17}$, el de la reforma competencial que introdujo en este tema la Ley $\mathrm{N}^{\circ} 20.050$, al derogar el antiguo art. 80 de la C.P.R. que atribuía a la Corte Suprema -a partir de la Carta de 1925- el conocimiento del proceso de inaplicabilidad, y al trasladarlo a su sede natural, que es el T.C., en el nuevo art. $93 \mathrm{~N}^{\circ} 6^{\circ}$, que dice así:

"Art. 93. Son atribuciones del Tribunal Constitucional:

$6^{\circ}$ Resolver, por la mayoría de sus miembros en ejercicio, la inaplicabilidad de un precepto legal cuya aplicación en cualquier gestión que se siga ante un tribunal ordinario o especial, resulte contraria a la Constitución."

\section{$5.2 \mathrm{La}$ esclarecedora redacción del art. $93 \mathrm{~N}^{\circ} 6$}

Si la redacción del antiguo art. 80 -hoy derogado- dejaba algún margen para confundir el carácter particular y concreto de la inaplicabilidad con la substancia general y abstracta de la inconstitucionalidad de la ley, no obstante la distinta naturaleza y carácter de ambas instituciones, la redacción actual obliga al sentenciador de inaplicabilidad a examinar precisamente la incidencia que la aplicación del precepto legal cuestionado al caso concreto en que se pretende aplicar resulta, o no, contraria a la Constitución.

Esto es lo que ha venido haciendo, con absoluta fidelidad a la atribución transcrita, el Tribunal Constitucional en todas sus sentencias de inaplicabilidad de preceptos legales.

\subsection{Titularidad de la acción}

5.3.1. La acción de inaplicabilidad corresponde, naturalmente, a la parte en un juicio civil o criminal o al interesado en una gestión, en los

17 Existe la opinión divergente del profesor Alejandro Silva Bascuñán, quien estima que el examen de los hechos que es uno de los aspectos que implica la acción de inaplicabilidad, es propio de la justicia ordinaria y no del T.C. 
cuales se invoque o aparezca que es aplicable un precepto de rango legal cuya aplicación en el asunto que le concierne resultaría contraria a la Constitución.

5.3.2. La reforma constitucional, siguiendo un mecanismo original del art. 163 de la Constitución española de 1978, ha extendido el ámbito natural de titularidad de la acción, al juez que conoce el asunto en que la cuestión se plantea. Dice el art. 93 inc. $11^{\circ}$, en su primera parte: "En el caso del número $6^{\circ}$, la cuestión podrá ser planteada por cualquiera de las partes o por el juez que conoce del asunto".

Se presenta la duda de si el juez, ante una cuestión de inaplicabilidad que se le plantee tiene el deber o está facultado para recurrir al T.C. Hay quienes piensan que se trata de un deber.

Discrepamos de esta opinión, en presencia de la fuerza directamente vinculante de la Constitución, conforme a su art. $6^{\circ}$. En efecto, si un juez no tiene dudas acerca de que el precepto que se invoca es contrario a la Constitución, debe inaplicarlo en virtud del deber ministerial que le impone el art. $6^{\circ}$, que no le obliga a consultar a nadie. En cambio, si tiene una razonable duda -o un irrazonable temor de decidir por sí mismo- puede plantear el asunto al T.C. Abona esta convicción el texto citado, al señalar que "la cuestión podrá ser planteada por cualquiera de las partes o por el juez que conoce del asunto."

\subsection{Trámite previo de admisibilidad}

Agrega el inciso $11^{\circ}$ del art. 93 que "Corresponderá a cualquiera de las salas del Tribunal declarar, sin ulterior recurso, la admisibilidad de la cuestión siempre que verifique la existencia de una gestión pendiente ante el tribunal ordinario o especial, que la aplicación del precepto legal impugnado pueda resultar decisivo en la resolución de un asunto, que la impugnación esté fundada razonablemente y se cumplan los demás requisitos que establezca la ley". El trámite de admisibilidad está regulado, además, por el art. 47-F del Proyecto de L.O.C. del T.C.

Los arts. 47-A y 47-C del Proyecto (en su actual estado de tramitación) señalan "los demás requisitos que debe cumplir el requerimiento."

\subsection{Efecto suspensivo del procedimiento en que incide el requerimiento}

Este no es un efecto automático sino que debe ser analizado y resuelto por una sala del T.C. En su modelo español (art. 163 C.E.), los efectos que establezca la ley... "en ningún caso serán suspensivos".

Dice el inciso $11^{\circ}$, citado, del art. 93 C.P.R. que, a la misma sala que declare la admisibilidad de la cuestión "... le corresponderá resolver la sus- 
pensión del procedimiento en que se ba originado la acción de inaplicabilidad por inconstitucionalidad".

\section{IMPROCEDENCIA DE LA ACCIÓN DE INAPLICABILIDAD DE LOS TRATADOS}

No obstante desprenderse claramente de la nueva regulación constitucional de los Tratados Internacionales (art. 54), el art. 47-B del Proyecto señala expresamente que no procederá la acción de inaplicabilidad respecto de tratados internacionales ratificados por Chile y que se encuentren vigentes.

\section{TRAMITACIÓN DEL REQUERIMIENTO}

Este importante aspecto es materia de la LOC. del T.C., cuya reforma está en tramitación ante la $\mathrm{H}$. Senado de la República, por lo que deberá esperarse la entrada en vigencia del texto definitivo.

\section{EFECTOS DE LAS SENTENCIAS DE INAPLICABILIDAD}

Cabe recordar que, como toda sentencia del T.C., se trata de una sentencia de única instancia, de supremo rango e insusceptible de recurso alguno salvo la facultad del Tribunal de rectificar los errores de becbo en que pudiera haber incurrido (art. 94 inc. $1^{\circ}$, CPR.)

El efecto propio de una sentencia estimatoria, es decir, de aquella que acoge la inaplicabilidad -sea a petición de parte o en respuesta a la consulta del juez de la causa-consiste en impedir que en esa causa pueda aplicarse, en cualquiera instancia o recurso judicial, el precepto declarado inaplicable a ella.

Un efecto secundario -pero no menos importante de dicha sentencia- consiste en que ello configura, en el sistema de nuestra Constitución, un tequisito indispensable para poder interponer, en contra del mismo precepto legal declarado inaplicable, la acción de inconstitucionalidad o su declaración de oficio (Art. 93 inc. $1^{\circ} \mathrm{N}^{\circ} 7$ e inciso $12^{\circ}$ C.P.R.).

\section{CONCLUSIÓN GENERAL}

Es nuestra convicción que la magistral redacción del art. $93 \mathrm{~N}^{\circ} 6$ de la C.P.R. reformada por la Ley $\mathrm{N}^{\circ} 20.050$, esclareció el verdadero sentido de la inaplicabilidad de un precepto legal, puso término a una interpre- 
tación reductiva y perturbadora a la que pudo prestarse el texto constitucional derogado por ella (Art.80 de la CPR. original) y restituyó a este instituto jurídico las alas que mantuvo aprisionadas por tanto tiempo.

\section{BIBLIOGRAFÍA}

- ANDrade Geywitz, C. (1963) Elementos de Derecho Constitucional Chileno. Santiago: Editorial Jurídica de Chile.

- Estévez GAZMURI, C. (1949) Elementos de Derecho Constitucional Cbileno. Santiago: Editorial Jurídica de Chile.

- Huneeus, J. (1891) La Constitución ante el Congreso. Tomo II. Santiago: Imp. Cervantes.

- GARCÍA DE ENTERRÍA, E. (1984) La Constitución como norma y el Tribunal Constitucional. Madrid: Civitas.

- Raveau, R. (1939) Tratado Elemental de Derecho Constitucional Cbileno y Comparado. Santiago: Editorial Nascimento.

- RoldÁN, A. (1914) Elementos de Derecho Constitucional de Cbile. Santiago.

- SILVA BASCUÑ̃́N, A. (1963) Tratado de Derecho Constitucional. T. III. Santiago: Editorial Jurídica de Chile.

- Silva BASCuñán, A. (1988) "Efectos de la resolución de Constitucionalidad". Revista Chilena de Derecho, Vol. 15, Nos 2-3.

- Silva BASCUÑ́n, A. (2002) Tratado de Derecho Constitucional. T. VIII. Santiago: Editorial Jurídica de Chile. 